\title{
SIJAPIN ATASI KEBOSANAN PJJ MATEMATIKA KELAS VIIA SMP NEGERI 12 SEMARANG
}

\author{
SIJAPIN to Overcome Students' Boredom of Mathematics Distance Learning in in \\ Class VIIA SMP Negeri 12 Semarang
}

\author{
Ani Amimah \\ SMP Negeri 12, Kota Semarang, Jawa Tengah, E-mail korespondensi: aniamimah3@gmail.com
}

\begin{abstract}
Distance learning using information and communication technology brings some problems for some teachers in Indonesia, including the writer. Students learn independently without explanation from the teacher. This condition causes learning boredom for some students.
\end{abstract}

SiJaPin (Sinau bareng Jateng Pintar) or Learning with Smart Central Java is an effort to overcome students boredom of Mathematics distance learning in Class VIIA SMP Negeri 12 Semarang .

The implementation of SiJaPin is 1) Design and preparation stage 2) Implementation stage. The results of SiJaPin implementation are results of learning final evaluation, on the first day of learning, class VIIA students get an average score of 71.75 and 83.25 on the second day. Questionnaire of students' reflection on distance learning with SiJaPin: 18 students stated that they felt happy, 21 said they could overcome their boredom, and 10 said that they were motivated to learn. Supporting factors for the implementation of SiJaPin are the support from fellow teachers and principal, the enthusiasm of students, adequate facilities by the provided rooms, laptops, handphones and internet. Inhibiting factors for the implementation of SiJaPin 1) limitation of the teacher in monitoring internet signal, that makes students cannot hear teacher's voice when starting the lessons, 2) the teacher is less careful that makes typing errors on the PPT slides, 3) lack of coordination on the previous days, 4) next lesson plan by video conference using attractive PPT.

Keywords: SiJaPin, boredom, distance learning.

\begin{abstract}
ABSTRAK
Pembelajaran Jarak Jauh (PJJ) menggunakan TIK menimbulkan permasalahan bagi guru di Indonesia, termasuk penulis. Peserta didik belajar mandiri tanpa penjelasan dari guru. Kondisi ini menimbulkan kebosanan belajar pada peserta didik. Upaya mengatasi kebosanan peserta didik dalam PJJ matematika Kelas VIIA SMP Negeri 12 Semarang dilakukan melalui pembelajaran dengan SiJaPin (Sinau bareng Jateng Pintar).

Implementasi SiJaPin yakni 1) Tahap perencanaan dan persiapan 2) Tahap pelaksanaan. Hasil implementasi SiJaPin berupa hasil evalusi akhir pembelajaran, peserta didik kelas VIIA memperoleh nilai rata-rata 71.75 pada pembelajaran hari pertama dan 83,25 pada pembelajaran hari kedua. Angket refleksi peserta didik terhadap PJJ dengan SiJaPin: 18 peserta didik menyatakan merasa senang, 21 anak menyatakan dapat mengatasi kebosanan, dan 10 anak menyatakan dapat memotivasi untuk belajar. Faktor pendukung implementasi SiJaPin adalah adanya dukungan dari rekan guru maupun kepala sekolah, antusiasme peserta didik, fasilitas yang memadahi berupa penyediaan room, laptop, HP dan internet. Faktor penghambat implementasi SiJaPin 1) keterbatasannya guru dalam memantau sinyal internet, sehingga pada saat memulai pelajaran beberapa saat siswa tidak bisa mendengar suaranya, 2) tidak telitinya guru sehingga terdapat kesalahan pengetikan pada slide PPT, 3) kurangnya koordinasi pada hari sebelumnya 4)rencana pembelajaran berikutnya secara vicon dengan menggunakan PPT yang menarik.
\end{abstract}

Kata Kunci: SiJaPin, kebosanan, PJJ.

\section{PENDAHULUAN}

Pandemi covid-19 telah melanda di berbagai negara termasuk Indonesia. Pembatasan Sosial Berskala Besar (PSBB) diberlakukan di berbagai daerah agar pandemi ini tidak makin meluas. Selama PSBB, kegiatan yang diselenggarakan di tempat atau fasilitas umum harus dilaksanakan dalam bentuk pembatasan jumlah orang dan pengaturan jarak atau physical distancing. Namun, 
pembatasan ini tidak berlaku untuk supermarket, minimarket, pasar, toko, atau tempat penjualan obat dan peralatan medis, kebutuhan pangan, barang kebutuhan pokok, bahan bakar minyak dan gas serta energi.

Dunia pendidikan juga tidak lepas dari PSBB. Menteri Pendidikan dan Kebudayaan Republik Indonesia mengeluarkan Surat Edaran Nomor 4 Tahun 2020 tentang pelaksanaan kebijakan Pendidikan dalam Masa Darurat Penyebaran Coronavirus Disease (Covid-19). Atas dasar edaran tersebut, Dinas Pendidikan Kota Semarang melalui Surat Edaran No.P/2922/440/III/2020 tanggal 15 Maret 2020 tentang pencegahan covid-19, memutuskan bahwa sekolah diliburkan mulai 16 sampai 28 Maret 2020 dengan diberikan tugas dari guru. Berikutnya, melalui Surat Edaran No P/3294/4440/III/2020 tertanggal 26 Maret 2020, proses belajar yang secara daring/jarak jauh diperpanjang lagi.

Proses belajar mengajar secara jarak jauh dengan menggunakan media informasi dan komunikasi tersebut menimbulkan permasalahan bagi sebagian guru di Indonesia pada umumnya dan di Kota Semarang pada khususnya karena belum terbiasa menggunakan media seperti ini. Kemampuan guru menggunakan Teknologi Informasi dan Komunikasi untuk kegiatan pembelajaran masih tergolong minim.

Demikian juga yang terjadi di SMP Negeri 12 Semarang, sebagian besar guru yang rata-rata usia di atas 50 mengalami kesulitan dalam menggunakan IT dalam pembelajaran jarak jauh. Sebenarnya pihak sekolah 2 (dua) kali melaksanakan In House Training penggunaan IT, namun ini dilakukan sebatas untuk keperluan penilaian. Hal ini disebabkan selama 3 tahun terakhir SMP Negeri 12 Semarang melaksanakan penilaian berbasis computer (CBT). Sehingga setiap guru harus memiliki kemampuan mengoperasikan komputer dalam melaksanakan penilaian ini, mulai dari membuat soal, mengupload, sampai mengunduhnya. IHT ini juga dimaksudkan untuk meningkatkan kemampuan guru dalam melaksanakan pengisian e-raport mulai perencanaan penilaian, sampai pengolahan nilai akhir.

Kebijakan tentang pembelajaran jarak-jauh disikapi dengan baik oleh seluruh guru sesuai kemampuan masing-masing. Sebagian guru membuat rangkuman materi dan tugas yang diberikan kepada peserta didik melalui Whatsapp, memberikan rangkuman materi dan tugas melalui Microsoft Office 365 pada fitur forms. Materi dikemas dalam PPT (power point) sedangkan soal atau tugas dikemas dalam microsoft forms. Pembelajaran dilakukan secara mandiri tanpa penjelasan dari guru. Kondisi semacam ini berlangsung beberapa bulan sehingga menimbulkan kebosanan pada peserta didik, yang berdampak pada menurunnya hasil belajar peserta didik.

Beruntunglah saya mengikuti grup whatsapp yang adminnya adalah master trainer dari BPTIK DIKBUD Jateng. Beliau dengan cekatan menawarkan kepada anggota grup yang sebagain besar anggotanya adalah pendidik. Beliau memberikan fasilitas pembelajaran online dengan memberikan room secara gratis yang bisa digunakan untuk pembelajaran jarak jauh dan room bisa di masuki oleh semua siswa di nusantara ini tanpa terkecuali dengan gratis. Karena hati pendidik saya yang merasa belum puas dengan cara pembelajaran sebelumnya, maka saya mendaftarkan diri untuk bergabung di dalam grup whatsaap baru yang anggotanya para pendidik yang antusias dengan pembelajaran. Dalam waktu semalam kita belajar masuk ke room, share materi berikut mendengarkan dan mencoba semua fitur-fitur di dalamnya.

Pembelajaran daring tersebut memfasilitasi pada jenjang SD, SMP, SMA, dan SMK semua mapel dalam Kegiatan Sinau bareng Jateng Pintar (SiJaPin) melalui fasilitas meeting pada aplikasi Teams yang diselenggarakan oleh BPTIK Dikbud Dinas Pendidikan dan Kebudayaan Provinsi Jawa Tengah.

Berangkat dari dorongan dalam diri tersebut penulis bersemangat melaksanakan pembelajaran secara daring melalui fasilitas meeting pada aplikasi Teams BPTIK Dikbud Disdikbud Jateng yang merupakan pengalaman pertama yang sangat berharga bagi penulis sebagai solusi untuk mengatasi kebosanan peserta didik. Berdasarkan seluruh uraian tersebut, penulis menyusun laporan pengalaman terbaik dalam sebuah best practice yang berjudul "SiJaPin Atasi Kebosanan Belajar 
pada PJJ Matematika Kelas VIIA SMP Negeri 12 Semarang”. Dipakainya kelas VIIA dalam best practice ini karena kebetulan pada hari itu penulis mengajar di kelas VIIA.

Berdasarkan uraian pada latar belakang masalah, maka permasalahan yang muncul adalah bagaimana: 1) implementasi SiJaPin dalam mengatasi kebosanan belajar pada pembelajaran jarak jauh matematika bagi peserta didik kelas VIIA SMP Negeri 12 Semarang; 2) hasil implementasi SiJaPin dalam mengatasi kebosanan belajar pada pembelajaran jarak jauh matematika bagi peserta didik kelas VIIA SMP Negeri 12 Semarang; 3) Apa saja yang menjadi faktor pendukung implementasi SiJaPin dalam mengatasi kebosanan belajar pada pembelajaran jarak jauh matematika bagi peserta didik kelas VIIA SMP Negeri 12 Semarang; 4) Apa saja yang menjadi faktor penghambat implementasi SiJaPin dalam mengatasi kebosanan belajar pada pembelajaran jarak jauh matematika bagi peserta didik kelas VIIA SMP Negeri 12 Semarang; 5) Apa rencana pengembangan yang akan dilakukan setelah implementasi SiJaPin dalam mengatasi kebosanan belajar pada pembelajaran jarak jauh matematika bagi peserta didik kelas VIIA SMP Negeri 12 Semarang

Penulisan laporan best practice ini dilaksanakan dengan tujuan sebagai berikut: 1) mendeskripsikan implementasi SiJaPin dalam mengatasi kebosanan belajar pada pembelajaran jarak jauh matematika bagi peserta didik kelas VIIA SMP Negeri 12 Semarang; 2) mendeskripsikan hasil implementasi SiJaPin dalam mengatasi kebosanan belajar pada pembelajaran jarak jauh matematika bagi peserta didik kelas VIIA SMP Negeri 12 Semarang; 3) mendeskripsikan faktor pendukung implementasi SiJaPin dalam mengatasi kebosanan belajar pada pembelajaran jarak jauh matematika bagi peserta didik kelas VIIA SMP Negeri 12 Semarang; 4) mendeskripsikan faktor penghambat dalam implementasi SiJaPin dalam mengatasi kebosanan belajar pada pembelajaran jarak jauh matematika bagi peserta didik kelas VIIA SMP Negeri 12 Semarang; 5) mendeskripsikan rencana pengembangan setelah implementasi SiJaPin dalam mengatasi kebosanan belajar pada pembelajaran jarak jauh matematika bagi peserta didik kelas VIIA SMP Negeri 12 Semarang.

Sedangkan manfaat penulisan laporan best practice ini diharapkan dapat memberikan manfaat baik teoretis maupun praktis. 1) Manfaat Teoretis : Penulisan karya ilmiah ini diharapkan menambah khasanah ilmu pengetahuan untuk melakukan upaya yang relevan dalam pengembangan proses pembelajaran yang dapat mengatasi kebosanan peserta didik mengikuti Pembelajaran Jarak Jauh. 2) Manfaat Praktis : a) Menjadi referensi bagi guru, khususnya guru Matematika dalam mengembangkan proses pembelajaran yang dapat mengatasi kebosanan peserta didik mengikuti Pembelajaran Jarak Jauh. b) Menjadi acuan bagi sekolah dalam pengembangan proses pembelajaran yang dapat mengatasi kebosanan peserta didik mengikuti Pembelajaran Jarak Jauh.

\section{SiJaPin}

SiJaPin atau Sinau bareng Jateng Pintar adalah kelas online yang dimiliki oleh Balai Pengembangan Teknologi Informasi dan Komunikasi Pendidikan dan Kebudayaan (BPTIK DIKBUD) Dinas Pendidikan dan Kebudayaan Provinsi Jawa Tengah, yang dibuat dalam rangka memfasilitasi kegiatan belajar mengajar secara online bagi guru dan siswa masa pandemi covid19. Kegiatan kelas online ini menggunakan aplikasi Teams Meeting dari Microsoft. SiJaPin dirancang untuk pembelajaran yang asyik, diantaranya adalah belajar live dengan guru sehingga bisa bertanya jawab secara langsung dan mendapatkan materi serta soal latihan yang bisa digunakan untuk mengukur seberapa paham siswa dengan materi yang disampaikan. Kelas online ini untuk semua jenjang dari SD, SMP, SMA, dan SMK. Kegiatan SiJaPin berlangsung sejak 6-22 April 2020 untuk SD, SMP, SMA, dan SMK. Sedangkan PAUD mulai 20-22 April 2020. Rekap aktivitas kegiatan SiJaPin telah disampaikan oleh tim BPTIK pada 24 April 2020, dalam Webinar Edu - Teknologi Sebagai Sarana Kolaborasi Potensi. Dalam Webinar Edu tersebut disampaikan bahwa jumlah total guru yang terlibat dalam SiJaPin sejumlah 114 guru. Jumlah siswa yang terlibat 5.850 siswa, sedangkan jumlah tatap muka 144 kali. Adapun peserta didik/siswa yang berpartisipasi menjadi peserta berasal dari beberapa kota di provinsi jawa tengah diantaranya adalah; 1) Semarang, 2) Kota Semarang, 3) 
Pati, 4) Pekalongan, 5) Blora, 6) Kendal, 7) Kudus, 8) Pati, 9) Demak, 10) Karanganyar, 11) Wonosobo, 12) Kebumen, 13) Kota Surakarta, 14) Sragen, dan 15) Klaten.

Berangkat dari kesuksesan kegiatan ini dan adanya ketentuan perpanjangan PJJ masa pandemi, maka pimpinan BPTIK DIKBUD Jateng memperpanjang SiJaPin sampai dengan tanggal 16 Mei 2020 (https://hilga.gurusiana.id/article/2020/4/sijapin-diperpanjang-ayo-ramaikan4885034?bima_access_status=not-logged diunduh 10 Mei 2020)

\section{Hakikat Belajar}

Menurut Syah (2020: 63) belajar adalah kegiatan yang berproses dan merupakan unsur yang sangat fundamental dalam penyelenggaraan setiap jenis dan jenjang pendidikan. Ini berarti bahwa berhasil atau gagalnya pencapaian tujuan pendidikan itu amat bergantung pada proses belajar yang dialami siswa baik ketika dia berada di sekolah maupun di lingkungan rumah atau keluarganya sendiri.

Biggs dalam Syah (2020: 67) mendefisikan belajar dalam tiga macam rumusan yaitu rumusan kuantitatif, rumusan institusional, dan rumusan kualitatif. Secara kuantitatif (ditinjau dari jumlah), belajar berarti kegiatan pengisian atau pengembangan kemampuan kognitif dengan fakta sebanyakbanyaknya. Jadi belajar dalam hal ini dipandang dari sudut berapa banyak yang dikusasi siswa. Secara institusional (tinjauan kelembagaan), belajar dipandang sebagai proses validasi (pengabsahan) terhadap penguasaan siswa atas materi-materi yang telah ia pelajari. Bukti institusional siswa yang telah belajar dapat diketahui dalam hunungannya dengan proses mengajar. Ukurannya ialah semakin baik mutu mengajar yang dilakukan guru maka akan semakin baik pula mutu perolehan siswa yang kemudian dinyatakan dalam dalam bentuk skor atau nilai. Adapun pengertian belajar secara kualitatif (tinjauan mutu) ialah proses memperoleh arti-arti dan pemahaman-pemahaman serta cara-cara menafsirkan dunia di seliling siswa. Belajar dalam pengertian ini difokuskan pada tercapainya daya pikir dan Tindakan yang berkualitas untuk memecahkan masalah-masalah yang kini dan nanti dihadapi siswa.

Menurut Winkel dalam Wahab (2015 : 17) belajar adalah suatu aktivitas mental/psikis yang berlangsung dalam interaksi aktif dengan lingkungan, yang menghasilkan perubahan-perubahan dalam pengetahuan-pemahaman, keterampilan, dan nilai-sikap. Perubahan itu bersifat secara relatif konstan dan berbekas.

Belajar menurut Hilgrad dalam Sanjaya (2006: 110) adalah proses perubahan melalui kegiatan atau prosedur latihan baik latihan di dalam laboratorium maupun dalam lingkungan alamiah. Belajar bukanlah sekedar mengumpulkan pengetahuan. Belajar adalah proses mental yang terjadi dalam diri seseorang, sehingga menyebabkan munculnya perubahan perilaku. Aktivitas mental itu terjadi karena adanya interaksi individu dengan lingkungannya yang disadari.

Jadi, dari beberapa pengertian belajar di atas maka dapat disimpulkan bahwa belajar adalah semua aktivitas mental atau psikis yang dilakukan oleh seseorang sehingga menimbulkan perubahan tingkah laku yang berbeda antara sesudah belajar dan sebelum belajar.

\section{Kebosanan Belajar}

Menurut Syah (2020: 180) secara harfiah jenuh artinya padat atau penuh sehingga tidak mapu lagi memuat apapun. Selain itu juga dapat berarti jemu atau bosan. Menurut Reber dalam Syah (2020: 181) Kejenuhan belajar adalah rentang waktu tertentu yang digunakan untuk belajar, tetapi tidak mendatangkan hasil. seorang siswa yang mengalami kejenuhan belajar merasa seakan-akan pengetahuan dan kecakapan yang diperoleh dari belajar tidak ada kemajuan.

Faktor penyebab kejenuhan (kebosanan) belajar diantaranya karena siswa telah kehilangan motivasi dan konsolidasi salah satu tingkat ketrampilan tertentu sebelum siswa tertentu sampai pada tingkat ketrampilan berikutnya (Chaplin dalam Syah 2020:181). Salah satu cara mengatasinya adalah dengan memberikan motivasi dan stimulasi baru agar siswa terdorong untuk belajar lebih giat dari pada sebelumnya. 


\section{PJJ (Pembelajaran Jarak Jauh)}

Sederhananya, pembelajaran jarak jauh adalah pendidikan yang diajarkan dari jarak jauh, tanpa ruang kelas secara fisik. Secara historis, istilah pembelajaran jarak jauh utamanya terkait dengan program perguruan tinggi yang memungkinkan mahasiswanya belajar dari jarak jauh. Sekarang, pembelajaran jarak jauh tidak hanya berlaku bagi mahasiswa di tingkat perguruan tinggi, namun juga siswa sekolah dasar, sekolah menengah pertama, dan menengah atas. (https://www.dropbox.com/id/business/resources/distance-learning diunduh 10 Mei 2020).

Ada beberapa cara yang berbeda untuk melaksanakan pembelajaran jarak jauh (PJJ) sebagai berikut.

\section{Konferensi video}

Format paling umum, dengan kelas dan pemberian pelajaran disajikan lewat panggilan konferensi atau seminar online atau webinar melalui Zoom. Dalam beberapa kasus, kelas-kelas seperti ini biasanya memiliki seorang pendidik yang memimpin pelajaran sementara pengajar lainnya biasanya ditugaskan untuk menjawab pertanyaan dan memantau siswa.

Cara-cara ini memungkinkan interaksi langsung antara siswa dan guru, sehingga menjadi jenis pembelajaran jarak jauh yang paling menggambarkan lingkungan ruang kelas tradisional.

\section{Pembelajaran asinkron}

Dalam pembelajaran asinkron, siswa didorong untuk bekerja secara mandiri. Tidak ada pelajaran kelompok, hanya tugas-tugas mingguan serta tenggat untuk diselesaikan masing-masing. Metode belajar mandiri seperti ini menawarkan fleksibilitas kepada siswa untuk mengetahui struktur dan jadwalnya sendiri, namun menawarkan interaksi kelompok dan komunikasi dengan guru yang jauh lebih sedikit.

\section{Jadwal terbuka}

Kuliah atau pelajaran terbuka serupa dengan pelajaran pembelajaran asinkron, hanya saja pembatasannya jauh lebih sedikit. Kuliah jadwal terbuka tidak memiliki tenggat mingguan, sehingga memungkinkan siswa melakukan berbagai hal pada waktunya sendiri dan lebih baik menyeimbangkan komitmen ekstrakurikuler mereka. Ini merupakan pilihan yang lebih disukai bagi pekerja purnawaktu, orang tua, atau siapa saja yang ingin belajar namun tidak memiliki jadwal untuk mengikuti mata kuliah tradisional.

Setiap lembaga memiliki metode serta strukturnya sendiri-sendiri untuk pembelajaran jarak jauh yang kemungkinan akan sesuai dengan salah satu kategori tersebut, atau mungkin gabungan dari berbagai jenis yang berbeda. Pendidikan asinkron dan jadwal terbuka jauh lebih umum untuk mata kuliah pendidikan tinggi.

\section{Media Belajar}

Menurut Arsyad (2011:3) pengertian media dalam proses belajar mengajar cenderung diartikan sebagai alat-alat grafis, photografis atau elektronis untuk menagkap, memproses dan Menyusun Kembali informasi visual atau verbal. Apabila media-media itu membawa pesan-pesan atau informasi yang bertujuan instruksional atau mengandung maksud-maksud pengajaran maka media itu disebut media pembelajaran.

Hamalik dalam Arsyad (2011:15) mengemukakan bahwa penggunaan media pembelajaran dalam proses belajar mengajar dapat membangkitkan keinginan dan minat yang baru, membangkitkan motivasi dan rangsangan kegiatan belajar, dan bahkan membawa pengaruh-pengaruh psikologis terhadap siswa.

Menurut Ibrahim dalam Arsyad (2011: 16) mengatakan bahwa media pembelajaran membawa dan membangkitkan rasa senang dan gembira bagi murid-murid dan memperbarui semangat mereka, membatu memantapkan pengetahuan pada benak para siswa serta menghidupkan pelajaran. 
Menurut Munhadi (2010:7) media pembelajaran dapat dipahami sebagai "segala sesuatu yang dapat menyampaikan dan menyalurkan pesan dari sumber secara terencana sehingga tercipta lingkungan belajar yang kondusif dimana penerimanya dapat lekukan proses belajar secara efisien dan efektif". Sedangkan fungsi media menurut Munhadi (2010:37-48) adalah 1) Fungsi sebagai sumber belajar; 2) Fungsi semantic yakni kemampuan media dalam menambah perbendaharaan kata (simbol verbal) yang makna atau maksudnya benar-benar dipahami anak-anak didik (tidak verbalistik); 3) fungsi manipulatif, mengatasi batas-batas ruang dan waktu dan mengatasi keterbatasan indrawi; 4) fungsi psikologis, yang terdiri atas fungsi atensi yakni dapat meningkatkan perhatian (attention) siswa terhadap materi ajar, fungsi afektif yakni menggugah perasaan, emosi dan tingkat penerimaan atau penolakan siswa terhadap sesuatu, fungsi kognitif dinama semakin banyak siswa dihadapkan pada obyek-obyek maka semakin banyak wawasannya, fungsi imajinatif bahwa media pembelajaran dapat meningkatkan dan mengembangkan imajinasi siswa , fungsi motivasi artinya dapat mendorong siswa melakukan kegiatan belajar sehingga tujuan pembelajaran dapat tercapai; dan 5) Fungsi sosio-kultural yakni mengatasi hambatan sosiokultural antarpeserta komunikasi pembelajaran.

\section{Power Point}

Microsoft PowerPoint atau Microsoft Office PowerPoint atau PowerPoint adalah sebuah program komputer untuk presentasi yang dikembangkan oleh Microsoft di dalam paket aplikasi kantoran mereka, Microsoft Office, selain Microsoft Word, Excel, Access dan beberapa program lainnya

(https://www.google.com/search?ei=HAkYKizNY66rQGh35HoBA\&q=apa+itu+power+point\&oq =apa+itu+power+poit\&gs_lcp=CgZwc3ktYWIQARgAMgQIABANMgQIABANMgQIABANMg QIABANMgQIABANMgQIABANMgQIABANMgQIABANMgYIABANEB4yCAgAEA0QChA eOgcIABCwAxBDOgcIABBHELADOgcIABCxAxANOgYIABANEAo6CAgAEAgQDRAeULi UAVjToAFg_7gBaAFwAXgAgAGOAYgBqgeSAQM0LjWYAQCgAQGqAQdnd3Mtd216yAEJw AEB\&sclient=psy-ab diunduh 10 Mei 2020).

Microsoft Power Point memiliki 11 fungsi yakni: 1) sebagai sarana untuk mempermudah melakukan sebuah presentasi; 2) membuat materi presentasi berbentuk softcopy sehingga dapat diakses oleh berbagai perangkat gawai; 3) memudahkan pembuatan presentasi dalam bentuk slide yang menarik dengan fitur audio, video, gambar dan animasi serta template yang akan dipergunakan; 4) mempermudah dalam proses pemebuatan, pengaturan, dan mencetak berbagai slide; 5) memberikan materi pembelajaran agar mudah dipahami pendengar atau audiens; 6) membuat bahan presentasi lebih hemat karena menggunakan softcopy dan tidak boros kertas; 7) menuturkan sebuah cerita menjadi lebih sederhana dan mudah dipahami audiens; 8) memengaruhi audiens atau pendengar dengan suatu gagasan teks, audio, dan visual; 9) memotivasi dan menginspirasi audiens agar tujuan penyampaian gagasan bisa lebih mudah dimengerti; 10) membuat audiens atau pendengar bisa mencetuskan ide atau gagasan baru sesuai keinginan yang melakukan presentasi; 11) menyampaikan permasalahan, solusi, dan cara kerja menjadi lebih sederhana.

(https://hot.liputan6.com/read/4466990/11-fungsi-microsoft-power-point-ketahui-fitur-andalandan-cara-

menggunakannya\#: :text=1.\%20Fungsi\%20Microsoft $\% 20$ Power\%20Point,untuk\%20mempermud ah\%20melakukan\%20sebuah\%20presentasi.\&text=3.\%20Fungsi\%20Microsoft\%20Power\%20Poin $\mathrm{t}$,serta\%20template\%20yang\%20akan\%20dipergunakan. Diunduh 10 Mei 2020)

\section{Kahoot!}

Sebuah platform pembelajaran berbasis permainan, digunakan sebagai teknologi pendidikan di sekolah dan lembaga pendidikan lainnya. Ini adalah permainan pembelajaran, "Kahoot!", adalah kuis pilihan ganda yang dibuat oleh pengguna yang dapat diakses melalui penjelajah web atau aplikasi Kahoot. 
Kahoot! bisa digunakan untuk meninjau pengetahuan peserta didik, sebagai penilaian formatif, atau sebagai pengistirahatan dari kegiatan kelas biasa. Kahoot! juga termasuk kuis trivia. (https://id.wikipedia.org/wiki/Kahoot!/ diunduh 10 Mei 2020).

\section{PEMBAHASAN MASALAH}

\section{Pemecahan Masalah dan Implementasinya}

Upaya mengatasi kebosanan peserta didik dalam PJJ matematika kelas VIIA SMP Negeri 12 Semarang Semester Genap Tahun Ajaran 2019/2020 dilakukan melalui pembelajaran dengan SiJaPin (Sinau Bareng bersama Jateng Pintar). SiJaPin adalah kelas online yang dimiliki oleh Balai Pengembangan Teknologi Informasi dan Komunikasi Pendidikan dan Kebudayaan (BPTIK DIKBUD) Dinas Pendidikan dan Kebudayaan Provinsi Jawa Tengah, yang dibuat dalam rangka memfasilitasi kegiatan belajar mengajar secara online bagi guru dan siswa masa pandemi covid-19. Kegiatan kelas online ini menggunakan aplikasi Teams Meeting dari Microsoft.

Implementasi pembelajaran jarak jauh melalui SiJaPin dalam mengatasi kebosanan peserta didik dalam belajar Matematika kelas VIIA SMP Negeri 12 Semarang mulai dari tahap perencanaan dan persiapan sampai pelaksanaan adalah seperti pada uraian berikut.

\section{1). Tahap perencanaan dan persiapan}

Langkah pertama setelah mendapat informasi adanya kesempatan mengajar dengan SiJaPin adalah mencari partner yang nantinya bertindak sebagai moderator. Sesuai ketentuan BPTIK DIKBUD Dinas Pendidikan dan Kebudayaan Provinsi Jawa Tengah bahwa untuk mendapatkan sertifikat setiap guru harus mengajar minimal 2 (dua) kali dan menjadi moderator 2 (dua) kali, maka saya menentukan jadwal mengajar adalah Senin 6 April 2020 didampingi oleh Ibu Kholif Mawadda sebagai pendamping (host) dan Rabu, 8 April 2020 didampingi Bapak Rahma Huda sebagai moderator dan pendamping berikut Senin, 20 April 2020 di dampingi oleh Ibu Yati sebagai moderator dan pendamping; dan Rabu, 6 Mei 2020 menjadi narasumber moderator dan sekaligus pendamping. Selasa, 7 April 2020 mendampingi Ibu Khamidah dari SMA Negeri 3 Slawi dan Kamis, 9 April 2020 mendampingi Bapak Sambiyono dari SMK Negeri 4 Semarang. Jadwal terlihat pada gambar berikut.

\begin{tabular}{|c|c|c|c|c|c|c|c|c|c|c|}
\hline \multirow{2}{*}{ Tangegal } & \multirow{2}{*}{ Waktu } & \multirow{2}{*}{ Jenjang } & \multirow{2}{*}{ Ig Kelas } & \multicolumn{4}{|c|}{ Pengajar } & \multicolumn{3}{|c|}{ Moderator } \\
\hline & & & & Nama & Kab/Kota & Sekolah & Mapel/Tema & Nama & $\mathrm{Kab} /$ Kota & Sekolah \\
\hline 06 April 2020 & $08.00 \cdot 09.30$ WIB & SD & IV & Syukron Zahidi Arrahmi & Kab. Purvorejo & SDN Girigondo & Tema 8 Daerah Tempat Tinggalku & Solehuddin Al Ayyubi & i Kab. Magelang & SON Banyuwangi 1 \\
\hline 06 April 2020 & $10.00-11.30 \mathrm{WIB}$ & SD & IV & ANDI RAHARJO, S.Pd. & Kab, Boyolali & SDN 1 Jipangan & Tema9 & & & \\
\hline & & & & & & & & & & \\
\hline 06 April 2020 & $08,00-09,30 \mathrm{WIB}$ & SMA & $x \mid$ & Heru prasetyo & Kab. Sragen & SMA NEGERI 1 SAMBUNGMACAN & Sejarah Indonesia & Sun Hadi & Demak & SMA Negeri 1 Dempet \\
\hline 06 April 2020 & $10,00-11,30$ WIB & 5MA & $x$ & Sutrisno, M. PKim & Kab. Pati & SMA Negeri 1 Batangan & Kimia & & & \\
\hline 06 April 2020 & $13.00 \cdot 14.30 \mathrm{WIB}$ & SMA & $x$ & SUN HADI & Kab. Demak & SMA NEGERI 1 DEMPET & BAHASA INDONESIA & Sambiyono & Kota Semarang & SMPN 12 Semarang \\
\hline 06 April 2020 & $08.00 \cdot 09.30 \mathrm{~W} / \mathrm{B}$ & SMK & $\mid x_{1}$ & Dwi Anto Punguth Widodo & Kab. Purworejo & Smk N 6 purworejo & Multimedia & AniAmimah & Kota Semarang & SMPN 12 Semarang \\
\hline 06 April 2020 & $10.00 \cdot 11.30$ WIB & SMK & $x$ & Kuntoro Triatmoko & Kab. Banjarnegara & SMKN 1 Wanayasa & Sistem Operasi & & & \\
\hline 06 April 2020 & $13.00 \cdot 14.30$ WIB & SMK & $x$ & Wawan Triyanto & Kab. Klaten & SMK Negeri 1 Gantiwarno & Sistem Komputer - Sistem Mikrokomputer & & & \\
\hline 06 April 2020 & $08.00-09.30 \mathrm{WIB}$ & SMP & VII & Pak Sotyana & Kab. Temanggung & SMPN 1 PARAKAN & IPA & Siti Mardliyah & Kab. Karanganyar & MTsN 2 Karanganyar \\
\hline 06 April 2020 & $13.00-14.30 \mathrm{WIB}$ & & VIII & TANDYO ARDHANA & Kab. Sukoharjo & SMP NEGERI 2 BAKI & Matematika/Bangun Ruang Sisi Datar & Puj Rahayu & Wonosobo & SMP N 1 Wadaslitang \\
\hline 06 April 2020 & $13,00-14,30$ WIB & SMP & VIII & Ani Amimah & Kota Semarang & SMPN 12 SEMARANG & Matematika/Bangun Ruang Sisi Datar & & & \\
\hline
\end{tabular}

Gambar 1. Screnshoot Jadwal mengajar di SiJaPin

Selanjutnya, melakukan persiapan yakni menyusun perangkat mengajar berupa: 1) dua buah Rencana Pelaksanaan Pembelajaran (RPP); 2) PowerPoint Presentation; 3) alat evaluasi berupa soal-soal yang dikemas dalam game pembelajaran dengan aplikasi Kahoot! dan PowerPoint, 4) daftar hadir melalui Microsoft Form; serta 5) angket refleksi peserta didik terhadap pembelajaran dengan SiJaPin melalui aplikasi Microsoft Form). RPP yang disusun ada 2 (dua) buah, pertama RPP dengan kompetensi dasar menganalisis dan menyelesaikan berbagai bangun datar segiempat dan kedua RPP dengan kompetensi dasar menurunkan rumus dan menentukan keliling dan luas segitiga

Agar pelaksanaan berjalan lancar maka dilakukan gladi bersih antara saya (sebagai guru yang mengajar) dan Ibu Yati yang bertindak sebagai pendamping sekaligus moderator. Kegiatan ini 
dilakukan malam hari sebelum hari pelaksanaan, yang dilakukan dalam gladi bersih ini adalah mempraktikkan jalannya kegiatan pembelajaran dan cara share screen power point maupun kahoot!.

Langkah selanjutnya adalah menyampaikan flyer yang telah dibuat BPTIK DIKBUD Jateng kepada peserta didik melalui Whatsapp Ketua Kelas VIIA SMP Negeri 12 Semarang untuk diteruskan kepada seluruh peserta didik kelas VIIA SMP Negeri 12 Semarang, sifatnya adalah wajib diikuti karena kebetulan bersamaan dengan jadwal pelajaran harian. Flyer untuk kelas VIIA, VIIB dan VIIC disebar melalui ketua kelas masing-masing yang sifatnya himbauan untuk mengikuti pembelajaran lewat SiJaPin, karena mereka ada yang harus mengikuti jadwal mata pelajaran lainnya selain melalui whatsapp ketua kelas.

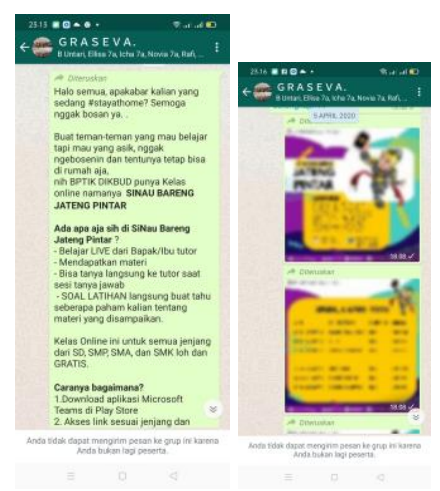

Gambar 2. Share flyer di WA

2). Tahap pelaksanaan

\section{Pembelajaran Hari Pertama}

Hari pertama pembelajaran matematika dengan SiJaPin dilakukan pada Selasa 6 April 2020 pukul 13.00 - 14.30. Dalam kesempatan ini pendamping (host) adalah Bapak Kholif Mawadda seorang teknisi dari BPTIKP. Pendamping bertugas membuka room pada aplikasi Teams dengan akun Jateng Pintar, mempersilahkan moderator untuk memulai kegiatan, dan membuat rekaman jalannya pembelajaran untuk disebar luaskan linknya ke grup Whatsapp Sinau bareng Jateng Pintar, dan mengarsipkannya untuk kepentingan BPTIK DIKBUD Jawa Tengah.

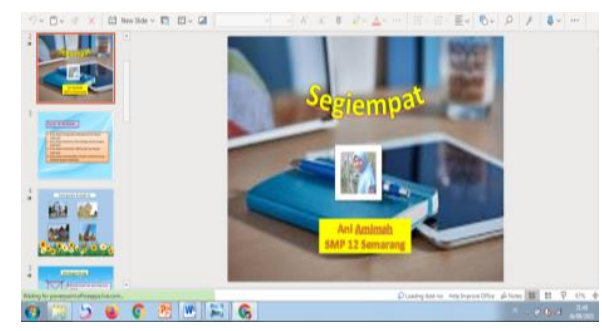

Gambar 3. Pendamping membuka room

Setelah kata pengantar dari pendamping, moderator yang juga di rangkap oleh Ibu Kholif Mawadda segera membuka acara dengan memberikan berbagai informasi terkait kegiatan yang akan dilakukan. Ibu Kholif Mawadda yang bertindak selaku moderator bertugas memandu jalannya pembelajaran yakni membuka pertemuan, memberikan kata pengantar kegiatan yang akan dilakukan, mengatur kapan pembelajaran dimulai, memandu sesi tanya jawab guru dan peserta 
didik, membuat simpulan dan menutup pertemuan. Moderator juga membuat notulen pembelajaran dengan SiJaPin.

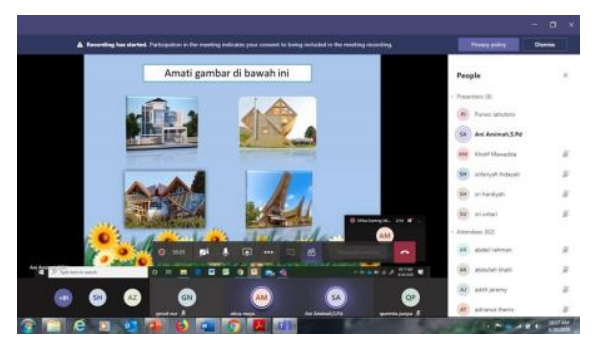

Gambar 4. Guru mengajar

Pembelajaran dimulai setelah dipersilakan oleh moderator. Guru membuka pelajaran dengan mengucap salam, menanyakan kabar dan mengajak peserta didik untuk berdoa. Guru membuka PowerPoint dan menyampaikan materi dengan cara ceramah kombinasi tanya jawab tentang bangun datar segiempat. Untuk menghindari verbalisme, pada awal pembelajaran dilakukan tanya jawab tentang gambar bangunan dan gedung yang terdapat bentuk bangun segiempat

Pada sesi tanya jawab terdapat beberapa siswa yang aktif, diantaranya Andika, Siti djawil, Atha zabrina, dan Tika. Untuk mengetahui capaian hasil pembelajaran, guru melaksanakan evaluasi dengan memutar aplikasi Kahoot! dengan 10 soal pilihan ganda. (soal terlampir). Moderator meminta peserta didik membuka tab baru dan aplikasi Kahoot! dan menuliskan kode PIN nya, 394985. Guru memulai game edukasi Kahoot! sambil terus memberikan motivasi supaya peserta didik berkerja keras dan mampu menjadi pemenang.

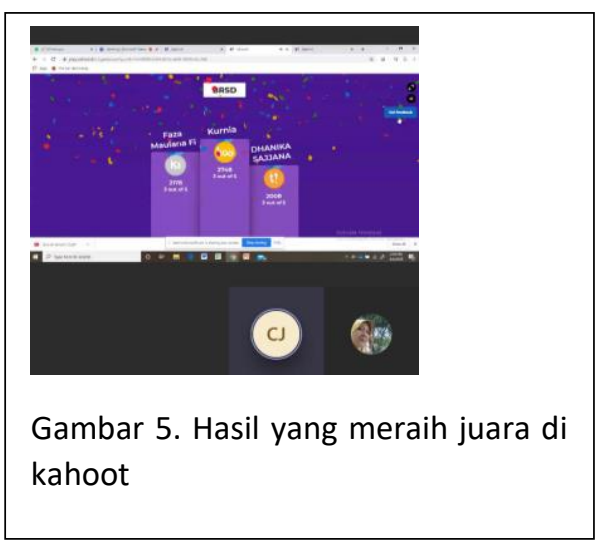

Dalam permainan edukatif ini yang berhasil menjadi juara I, II, dan III adalah Kurnia, Faza Maulana, Dhanika S. Pembelajaran hari pertama diakhiri dengan menarik simpulan yang melibatkan peserta didik, penyampaian pertemuan berikutnya, doa akhir dan salam. Moderator segera mengambil alih acara dengan kembali menyampaikan simpulan pembelajaran, ucapan terimakasih kepada BPTIK dan seluruh pihak yang terlibat dalam kegiatan pembelajaran ini, mengingatkan agar peserta didik Kembali mengikuti pembelajaran yang sama pada esok harinya, Rabu 20 April 2020 pada jam yang sama. Moderator mengucapkan salam penutup, pendamping menutup room meeting. Hasil rekaman pembelajaran dengan SiJaPin hari pertama ini bisa dilihat pada https://web.microsoftstream.com/video/185a692d-2608-4725-bdb5-c360fd43bb75. Link ini hanya bisa dibuka dengan menggunakan akun Jateng Pintar.

\section{Pembelajaran Hari Kedua}

Hari kedua pembelajaran matematika dengan SiJaPin dilakukan pada Rabu 20 April 2020 pukul 10.00- 11.30. Dalam kesempatan ini yang bertindak sebagai pendamping (host) adalah Bapak Rahma Huda Putranto sekaligus sebagai moderator. Materi pembelajaran adalah 
segitiga.Pembelajaran dimulai setelah dipersilakan oleh moderator. Guru membuka pelajaran dengan mengucap salam, menanyakan kabar dan mengajak peserta didik untuk berdoa. Guru membuka PowerPoint dan menyampaikan materi dengan cara ceramah bervariasi tanya jawab tentang menurunkan dan menentukan keliling luas segitiga. Untuk mempermudah pemahaman peserta didik terhadap materi, dalam PowerPoint ini juga menampilkan sebuah gambar benda nyata yang berbentuk segitiga. Pada kesempatan ini terdapat beberapa peserta didik yang aktif dalam tanya jawab yakni Bondan, Rizky Ramadhani, Husna. Ada juga siswa yang hadir dari Kota Kudus dan Kota Purbalingga yang begitu aktif dalam mengikuti pembelajaran.

Pada kegiatan akhir pembelajaran, peserta didik diajak untuk membuat simpulan, kemudian mengerjakan evaluasi (penilaian). Evaluasi pada hari kedua ini masih menggunakan kahoot! dengan kode pin 167322 dan yang berhasil menjadi juara adalah Haniya, Tika, dan Zulfa . Selanjutnya guru memberikan tugas individu untuk mengerjakan latihan menentukan keliling dan luas benda di rumah yang berbentuk segitiga dan mengirimnya melalui google clasroom. Latihan ini dikerjakan oleh hampir seluruh kelas VII SMP Negeri 12 Semarang. Rata-rata hasil latihan kelas VIIA adalah 83,25. Pembelajaran ditutup dengan doa akhir dan salam.

\section{SIMPULAN}

Implementasi SiJaPin mengatasi kebosanan belajar pada pembelajaran jarak jauh matematika bagi peserta didik kelas VIIA SMP Negeri 12 Semarang adalah seperti pada uraian berikut.

1. Tahap perencanaan dan persiapan diawali dengan mencari teman guru sebagai moderator, dilanjutkan mendaftar pada panitia, menyusun perangkat pembelajaran berupa RPP, media PowerPoint dan alat evalusi yang dikemas dalam Kahoot!, dan menyebar flyer kepada peserta didik. 2) Tahap pelaksanaan dimulai setelah pendamping membuka room meeting dengan aplikasi Teams dan mempersilakan moderator untuk membuka kegiatan. Guru memulai pembelajaran setelah diberikan kata pengantar oleh moderator. Guru membuka pelajaran dengan mengajak doa awal bersama, dan melakukan apersepsi. Kegiatan inti diisi ceramah bervariasi tanya jawab dengan menggunakan media PowerPoint. Pada kegiatan akhir guru mengajak peserta didik membuat simpulan bersama. Selanjutnya guru memberikan evaluasi akhir pembelajaran dengan aplikasi kahoot!. Guru mengakhiri pembelajaran dengan doa akhir. Kegiatan belajar bersama SiJaPin ditutup oleh moderator.

2. Hasil implementasi SiJaPin dalam mengatasi kebosanan belajar pada pembelajaran jarak jauh matematika bagi peserta didik kelas VIIA SMP Negeri 12 Semarang berupa hasil latihan (evalusi) pembelajaran, peserta didik kelas VIIA memperoleh nilai rata-rata 71,75 pada pembelajaran hari pertama dan 83,25 pada pembelajaran hari kedua. Angket refleksi peserta didik menujukkan 18 peserta didik menyatakan merasa senang, 21 anak menyatakan dapat mengatasi kebosanan, dan 10 anak menyatakan dapat memotivasi untuk belajar.

3. Faktor pendukung implementasi SiJaPin dalam mengatasi kebosanan belajar pada pembelajaran jarak jauh Matematika bagi peserta didik kelas VIIA SMP Negeri 12 Semarang adalah adanya dukungan dari rekan-rekan guru maupun kepala sekolah, antusisme peserta didik, fasilitas yang memadahi berupa penyediaan room, laptop, HP dan internet.

4. Faktor penghambat implementasi SiJaPin dalam mengatasi kebosanan belajar pada pembelajaran jarak jauh Matematika bagi peserta didik kelas VIIA SMP Negeri 12 Semarang adalah 1) keterbatasannya guru dalam memantau sinyal internet ataupun wifi, sehingga pada saat memulai pelajaran beberapa saat tidak siswa tidak bisa mendengar suaranya, 2) tidak telitinya guru sehingga terdapat kesalahan pengetikan pada slide PPT, seharusnya tanda tambah kesalahan pengetikan menjadi sama dengan , 3) kurangnya koordinasi pada hari sebelumnya sehingga sebagian peserta didik tidak siap untuk melaksakannya evaluasi pembelajaran dengan Kahoot!. 
5. Rencana pengembangan setelah implementasi SiJaPin mengatasi kebosanan belajar pada pembelajaran jarak jauh matematika bagi peserta didik kelas VIIA SMP Negeri 12 Semarang adalah guru akan melaksanakan pembelajaran berikutnya secara vicon dengan menggunakan PowerPoint yang lebih menarik dan melakukan kegiatan penilaian akhir pembelajaran dengan aplikasi game yang variatif, dan guru akan terus meningkatkan kompetensi dalam menggunakan Teknologi Informasi dan Komunikasi sehingga pelajaran jarak jauh akan terasa lebih menyenangkan dan tidak membosankan bagi peserta didik.

\section{SARAN}

Berdasarkan simpulan tersebut, disarankan bagi guru matematika maupun guru mata pelajaran lainnya dapat mencoba penggunaan strategi pembelajaran sejenis SiJaPin, yakni pembelajaran secara video conference dengan aplikasi Microsoft Teams atau sejenisnya, dan menggunakan media PPT yang menarik serta alat evalusi yang dikemas dalam berbagai game edukasi seperti Kahoot!, agar pembelajaran dirasa menyenangkan dan tidak menimbulkan kebosanan pada peserta didik. Dalam menggunakan strategi mengajar seperti ini hendaknya dimodifikasi sesuai dengan sifat dan karakteristik keilmuannya.

\section{DAFTAR PUSTAKA}

Arsyad, Azhar, 2011. Media Pembelajaran. Jakarta: PT Rajagrafindo Persada

Sanjaya,Wina, 2006. Strategi Pembelajaran Berorientasi Standar Proses Pendidikan. Jakarta: Kencana Prenada Media.

Syah, Muhibin, 2020. Psikologi Belajar. Depok: PT Rajagrafindo Persada

Wahab, Rohmalina, 2018. Psikologi Belajar. Depok: PT Rajagrafindo Persada

https://hilga.gurusiana.id/article/2020/4/sijapin-diperpanjang-ayo-ramaikan-

4885034?bima_access_status=not-logged diunduh 10 Mei 2020

https://www.dropbox.com/id/business/resources/distance-learning diunduh 1 Juni 2020.

https://www.google.com/search?ei=HAkYKizNY66rQGh35HoBA\&q=apa+itu+power+point\&oq= apa+itu+power+poit\&gs_lcp=CgZwc3ktYWIQARgAMgQIABANMgQIABANMgQIABAN MgQIABANMgQIABANMgQIABANMgQIABANMgQIABANMgYIABANEB4yCAgAEA 0QChAeOgcIABCwAxBDOgcIABBHELADOgcIABCxAxANOgYIABANEAo6CAgAEAg QDRAeULiUAVjToAFg_7gBaAFwAXgAgAGOAYgBqgeSAQM0LjWYAQCgAQGqAQdn d3Mtd216yAEJwAEB\&sclient=psy-ab diunduh 10 Mei 2020

https://hot.liputan6.com/read/4466990/11-fungsi-microsoft-power-point-ketahui-fitur-andalan-dancara-

menggunakannya\#: :text=1.\%20Fungsi $\% 20$ Microsoft $\% 20$ Power\%20Point,untuk\%20memper mudah\%20melakukan\%20sebuah\%20presentasi.\&text=3.\%20Fungsi $\% 20$ Microsoft $\% 20$ Power \%20Point,serta\%20template\%20yang\%20akan\%20dipergunakan. Diunduh 10 Mei 2020

(https://id.wikipedia.org/wiki/Kahoot!/ diunduh 10 Mei 2020) 